\title{
Dietary Elimination of Soybean Components Enhances Allergic Immune Response to Peanuts in BALB/c Mice
}

\author{
Lisa M. Chang ${ }^{a}$ Ying Song ${ }^{a}$ Xiu-Min Li ${ }^{a, b}$ Hugh A. Sampson ${ }^{a, b}$ \\ Madhan Masilamani ${ }^{a, b}$ \\ a Jaffe Food Allergy Institute, Division of Allergy and Immunology, Department of Pediatrics, and ${ }^{b}$ Immunology Institute \\ and Mindich Child Health and Development Institute, Icahn School of Medicine at Mount Sinai, New York, N.Y., USA
}

\section{Key Words}

Genistein · Daidzein · Isoflavones · Food allergy ·

Rodent diet

\begin{abstract}
Background: Food allergy research is hampered by a lack of animal models that consistently mimic human food allergic responses. Laboratory mice are generally fed grain-based chow made with large amounts of soybeans rich in immunomodulatory isoflavones. We tested the role of dietary soy components in the induction of food allergic responses in the BALB/c mouse strain, which is known to be resistant to anaphylaxis when orally challenged by food allergens. Methods: Mice were fed a soy-free diet for 2 generations. After weaning, mice were maintained on the same diet or fed a diet containing soy isoflavones, i.e. genistein and daidzein, followed by weekly oral sensitizations with crude peanut extract plus cholera toxin and finally challenged at week 7 . The anaphylactic symptoms, body temperature, peanut-specific antibodies and mast cell degranulation were assessed. $\boldsymbol{R e}$ sults: Soy-free diet mice showed significantly higher anaphylactic symptom scores and mast cell degranulation after challenge and higher peanut-specific antibody levels than mice fed regular chow. Introduction of a regular soy diet or an isoflavone diet to soy-free diet mice significantly sup-
\end{abstract}

pressed the allergic reactions compared to the soy-free diet. Conclusion: Rodent diet is an important variable and needs to be taken into consideration when designing experiments involving animal models. Our results indicate that elimination of soy components from the diet enhances peanut sensitization in BALB/c mice. In addition to serving as a valuable tool to mimic human food allergy, the dietary influence on the immune response could have far-reaching consequences in research involving animal models.

(C) 2015 S. Karger AG, Basel

\section{Introduction}

Laboratory animal diets are often an overlooked variable in biomedical research. In spite of significant advances and availability of new formulations of rodent diets, the influence of specific dietary components of rodent diets in biomedical research is not fully appreciated. For over 50 years, countless animals have been bred and maintained on commercial soy-based diets without obvious detrimental results. Soybeans are inexpensive but nutritionally complete with essential amino acids and fatty acids. In addition, soybeans are an abundant source of immune-modulatory and phytoestrogenic compounds called isoflavones. Several reports show the impact of di-

\section{KARGER 125}

(c) 2015 S. Karger AG, Base

$1018-2438 / 15 / 1664-0304 \$ 39.50 / 0$

E-Mail karger@karger.com

www.karger.com/iaa
Correspondence to: Dr. Madhan Masilamani

Jaffe Food Allergy Institute, Division of Allergy and Immunology

Department of Pediatrics, Icahn School of Medicine at Mount Sinai

New York, NY 10029 (USA)

E-Mail madhan.masilamani@mssm.edu 
etary isoflavones on various aspects of animal research [1-5]. Circulating isoflavone levels are an important factor in research involving animal models. High plasma and urine isoflavone levels have been demonstrated in mice fed with standard chows [1]. While phytoestrogenic effects of isoflavones on animal physiology are well recognized, the specific influence of dietary isoflavones on the immune response is still not clear [6]. Significant batch-to-batch variations of isoflavone content in rodent chow are well documented $[2,3,7]$. These variations could influence the outcome of the research and also potentially affect reproducibility of experimental results. This issue is much more relevant to food allergy research.

$\mathrm{BALB} / \mathrm{c}$ and C57/BL6 mice are commonly used mouse strains in biomedical research. Several genetic alterations and knockout/-in mice are available in these strains. However, failure to develop anaphylaxis in response to ingestion of a food allergen prevents full utilization of these mice in food allergy research. Most mouse strains require an adjuvant to break mucosal tolerance and to mount an immune response to oral/intragastric sensitization with food allergens, with $\mathrm{BALB} / \mathrm{c}$ mice being among the best responders in terms of IgE response. Yet, BALB/c mice do not show detectable anaphylaxis following oral challenge with the allergen and a minimal response when challenged via the intraperitoneal route $[8,9]$. Allergenspecific IgE levels in $\mathrm{C} 3 \mathrm{H} / \mathrm{HeJ}$ and $\mathrm{C} 3 \mathrm{H} / \mathrm{HeOuJ}$ mice are significantly lower compared to $\mathrm{BALB} / \mathrm{c}$, but these mice readily develop anaphylaxis upon challenge, closely mimicking human food allergy $[8,10,11]$. A number of studies in these mouse models have contributed towards developing new therapies for peanut allergy [12]. We have shown that dietary isoflavones suppress peanut allergic symptoms in $\mathrm{C} 3 \mathrm{H} / \mathrm{HeJ}$ mice [10] and upper airway hypersensitivity in $\mathrm{BALB} / \mathrm{c}$ mice [13].

We tested the effect of eliminating dietary soy components on the induction of anaphylactic responses to peanut in 'soy-free' BALB/c mice, bred for 2 generations on a soy-free diet. The F2 generation of 'soy-free' mice was used for 2 specific reasons: (1) to prevent prior sensitization to peanut components (as several peanut allergens share amino acid homology with that of soy [14]) and (2) to reduce the neonatal exposure to soy isoflavones through the placenta or breast milk $[15,16]$. We found that by altering one single group of molecules (isoflavones) in the diet, the sensitization to peanut allergens can be influenced. The implications of these results reach far beyond food allergy, in areas such as the development of functional foods and nutraceuticals, novel dietary formulations for immune disorders, etc.

Rodent Dietary Components and Food Allergy in BALB/c Mice

\section{Materials and Methods}

This study was approved by the Institutional Animal Care and Use Committee. BALB/c mice (18-21 per group) were fed a regular rodent chow, or bred for 2 generations on a soy-free diet. After weaning, soy-free mice were maintained on soy-free chow (15 female, 6 male) or switched to a diet containing 1,500 p.p.m. genistein and daidzein (isoflavone diet; 14 female, 4 male) for 2 weeks. Mice were orally sensitized weekly with $10 \mathrm{mg}$ crude peanut extract (CPE) and $10 \mu \mathrm{g}$ cholera toxin as adjuvant. In weeks 6 and 7 , mice were challenged orally twice in 30-min intervals with $100 \mathrm{mg}$ $\mathrm{CPE}$. The anaphylactic reactions were scored, and the rectal temperatures were recorded after $30 \mathrm{~min}$ [10]. In week 7, $30 \mathrm{~min}$ after the oral challenge, mice were then challenged intraperitoneally with $9 \mathrm{mg}$ defatted peanut protein, and anaphylactic scores and temperatures were recorded 30 min later. The percentages of degranulated mast cells were scored in ear sections obtained $60 \mathrm{~min}$ after the final challenge. Serum peanut-specific antibody levels and plasma mouse mast cell protease-1 (mMCP-1) were measured by ELISA. DNA methylation changes in the IL4 promoter were assessed by pyrosequencing technology [17]. Detailed descriptions of methods and compositions of the diets are provided as supplementary material (online suppl. table 1; for all online suppl. material, see www.karger.com/doi/10.1159/000430497).

\section{Results}

Peanut-Induced Anaphylaxis in Soy-Free Mice

$\mathrm{BALB} / \mathrm{c}$ mice (18-21/group) were bred for 2 generations on a soy-free diet. After weaning, the F2 mice were maintained on the soy-free chow or switched to a diet containing 1,500 p.p.m. genistein and daidzein (isoflavone diet; fig. 1a). Control mice were fed a regular rodent chow (soy diet). Isoflavone levels were tested in pooled mouse sera by HPLC. BALB/c mice that were fed a soyfree diet for 2 generations showed very low or undetectable serum isoflavone levels compared to mice that were on a soy diet (regular chow; online suppl. table 2 and online suppl. fig. 1).

Mice (18-21/group) were orally sensitized weekly with $10 \mathrm{mg}$ CPE and $10 \mu \mathrm{g}$ of cholera toxin (fig. 1b). In week 7 , mice were orally challenged with $100 \mathrm{mg}$ of CPE, their anaphylactic scores and the rectal temperatures were recorded followed by an intraperitoneal challenge with $9 \mathrm{mg}$ defatted peanut protein, and anaphylactic scores and temperatures were recorded as described [10]. After oral challenge with peanut, $67 \%$ (14 out of 21 ) of soy-free mice showed symptoms of systemic anaphylaxis with severity varying from mild (score 1) to mild-moderate (score 2 ). In contrast, $42 \%$ ( 8 out of 19 ) of the mice fed regular chow (soy diet) showed anaphylactic symptoms which were significantly milder compared to those in soy-free mice [median: 1 vs. 0 , interquartile range (IQR): 1 vs. $1, p=0.033$; 


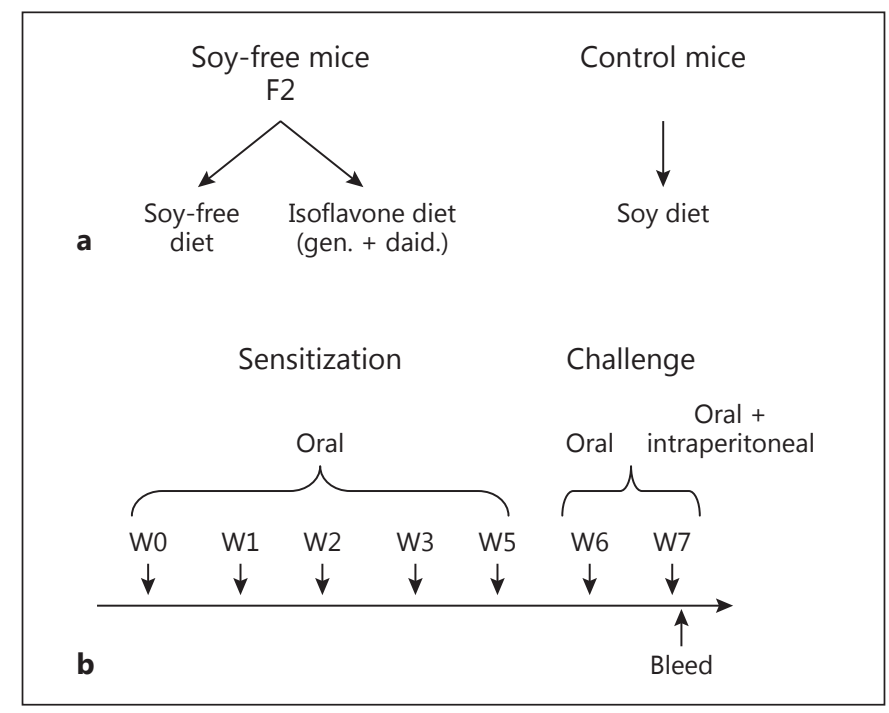

Fig. 1. Generation of soy-free mice and mouse group assignments. a BALB/c mice were maintained and bred for 2 generations with a soy-free diet. The F2 soy-free mice were either fed the same diet or a diet containing 1,500 p.p.m. genistein (gen.) and daidzein (daid.) for 2 weeks before sensitizing with peanuts. Control mice were fed regular rodent chow. b Peanut sensitization: 6- to 8-week-old $\mathrm{BALB} / \mathrm{c}$ mice were sensitized weekly with CPE and cholera toxin for 5 weeks and orally challenged with CPE (in weeks 6 and 7) or intraperitoneally (in week 7) with peanut protein extracts. The anaphylactic symptoms were scored, and body temperature was recorded $30 \mathrm{~min}$ after the final intraperitoneal challenge (for details, see Materials and Methods).

fig. 2a]. Interestingly, introduction of dietary isoflavones to soy-free mice $(\mathrm{n}=18)$ resulted in significantly reduced anaphylactic symptoms after oral challenge when compared to soy-free diet mice ( $\mathrm{n}=21$; similar to that seen in mice consuming regular chow; median: 1 vs. 0, IQR: 1 vs. $0, \mathrm{p}=0.0008$; fig. $2 \mathrm{a}$ ). When challenged by the intraperitoneal route, anaphylaxis was severer in all mice irrespective of diet. The anaphylaxis symptom scores were similar between soy-free diet mice and mice fed regular chow (soy diet; median: 2.5 vs. 2.5 , IQR: 0.5 vs. $0.5, p=0.16$ ) after intraperitoneal challenge (fig. 2b), but significantly higher than that of mice fed an isoflavone diet (median: 2.5 vs. 2.0 , IQR: 0.5 vs. $0, p=0.0077$ ). The symptom scores in the isoflavone diet mice were also lower when compared to mice fed regular chow (soy diet; median: 2.0 vs. 2.5, IQR: 0 . vs. $0.5, \mathrm{p}=0.031$; fig. $2 \mathrm{~b}$ ).

The anaphylactic symptoms after peanut challenge were closely correlated with the drop in body temperature. The body temperature change after oral challenge was subtle ranging from +0.6 to $-1.4^{\circ} \mathrm{C}$ in soy-free diet mice and +1.0 to $-0.4^{\circ} \mathrm{C}$ in mice fed a regular chow (soy diet) and significantly lower in soy-free diet mice compared to mice fed a regular chow (median: 0.1 vs. $0.3^{\circ} \mathrm{C}$, IQR: 0.5 vs. $0.55, \mathrm{p}=0.0071$; fig. $2 \mathrm{c}$ ). The drop in body temperature was dramatic after intraperitoneal challenge ranging from -2.9 to $-6.1{ }^{\circ} \mathrm{C}$ in soy-free diet mice and -0.2 to $-4.9^{\circ} \mathrm{C}$ in mice fed a regular chow. The drop in body temperature was significantly greater in soy-free diet mice compared to mice fed a regular chow (median: -4.4 vs. $-3.10^{\circ} \mathrm{C}, \mathrm{IQR}: 1.8$ vs. $\left.2.35, \mathrm{p}=0.0011\right)$ and also when compared to isoflavone diet mice (median: -4.4 vs. $-3.9^{\circ} \mathrm{C}$, IQR: 1.8 vs. $0.93, \mathrm{p}=0.0003$; fig. $2 \mathrm{~d}$ ). Naïve/ unsensitized, peanut-challenged mice from the respective groups failed to elicit any anaphylactic symptoms following oral or intraperitoneal challenges. Likewise, the change in body temperature was also minimal in all naïve/unsensitized, peanut-challenged mice.

\section{Dietary Soybean Components Suppress}

\section{Peanut-Induced Mast Cell Degranulation}

The anaphylactic scores and drop in body temperature correlate with the mast cell degranulation seen in ear sections obtained $60 \mathrm{~min}$ following intraperitoneal challenge and sacrifice. The percentages of degranulated mast cells were significantly higher in soy-free mice $(\mathrm{n}=21)$ than those fed the soy diet $(n=19$; median: 70 vs. $59 \%$, IQR: 10 vs. $6, \mathrm{p}=0.0001)$ or isoflavone $\operatorname{diet}(\mathrm{n}=18$, median: 70 vs. $59 \%$, IQR: 10 vs. $5.5, \mathrm{p}<0.0001$; fig. $3 \mathrm{a}$ ). However, the percentages of degranulated mast cells in mice fed the isoflavone diet did not differ when compared to mice fed the regular chow (median: 59 vs. $59 \%$, IQR: 5.5 vs. $6, \mathrm{p}=$ 0.133 ). $\mathrm{mMCP}-1$ is a $\beta$-chymase that is expressed in intestinal mast cells and is found in elevated levels during anaphylactic reactions. Plasma mMCP-1 levels were significantly elevated after peanut intraperitoneal challenge in soy-free diet mice $(\mathrm{n}=21)$ compared to mice fed the regular chow ( $\mathrm{n}=19$; median: $68.5 \mathrm{vs.} 27.5 \mathrm{ng} / \mathrm{ml}$, IQR: 167.4 vs. $19.4, \mathrm{p}=0.0059$; fig. $3 \mathrm{~b}$ ) but not when compared to isoflavone diet mice (median: 82.19 vs. $68.5 \mathrm{ng} / \mathrm{ml}$, IQR: 69.95 vs. $167.4, \mathrm{p}=0.46$ ). There were no significant differences in median mMCP-1 levels between the groups after oral peanut challenge (fig. 3c).

\section{Humoral Response to Peanut Sensitization Is}

Enhanced in Soy-Free Mice

Significantly higher levels of peanut-specific IgE, IgG1 and IgG2a were found in the serum of soy-free mice $(\mathrm{n}=12)$ when compared to mice fed the soy diet $(\mathrm{n}=19$; fig. 4), with peanut-specific antibody levels: IgE, median: 164 vs. $132 \mathrm{ng} / \mathrm{ml}$, IQR: 169.5 vs. $80, \mathrm{p}=0.0166$; IgG1, median: 62.4 vs. $40.1 \mu \mathrm{g} / \mathrm{ml}$, IQR: 7.65 vs. $24.45, \mathrm{p}=0.006$; 


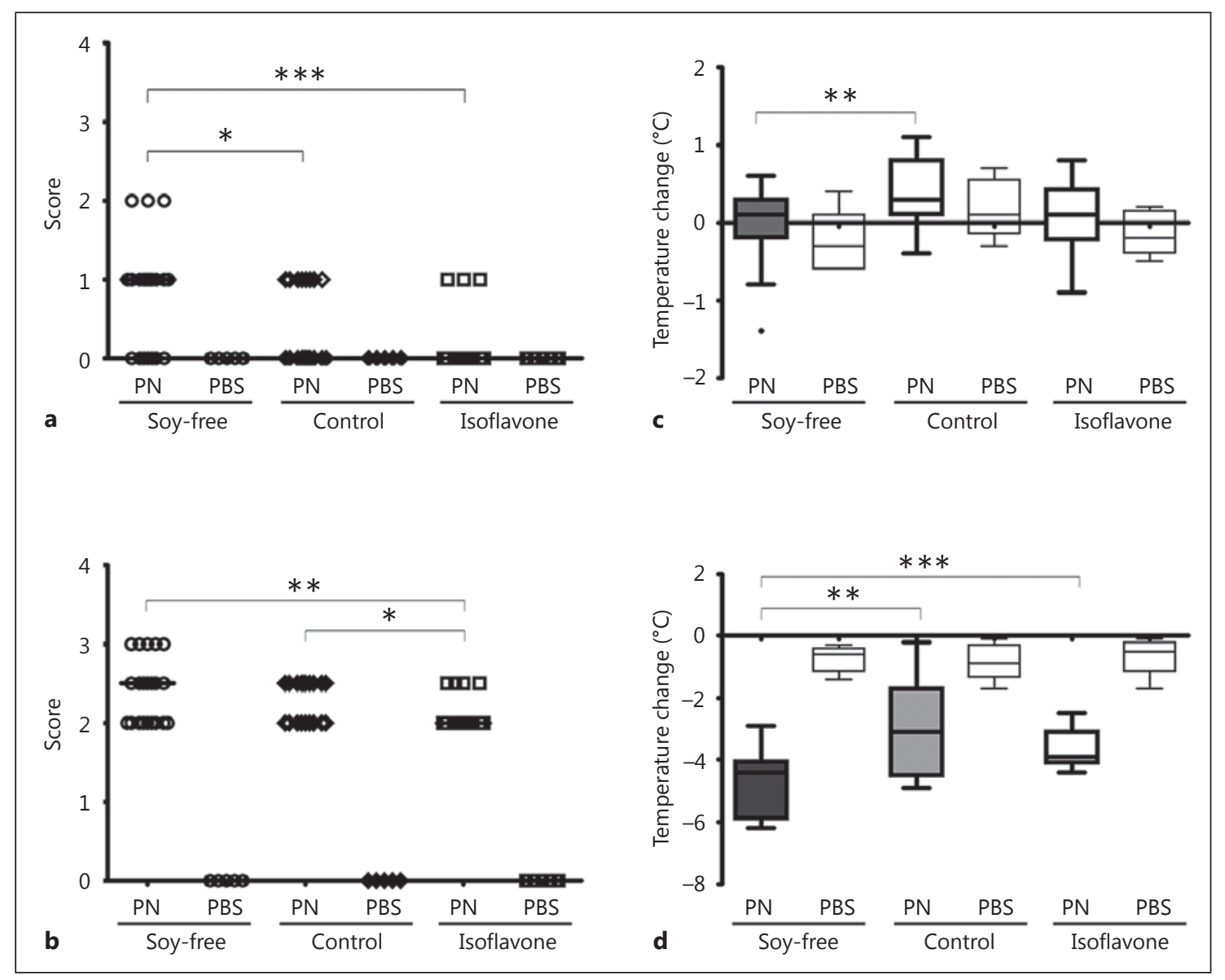

Fig. 2. $B A L B / c$ mice maintained with a soy-free $\operatorname{diet}(n=21)$, regular chow (control; $n=19$ ) or soy-free mice with an isoflavone diet $(n=18)$ were sensitized and challenged with peanut extracts, as detailed in the Materials and Methods. The anaphylactic scores were recorded $60 \mathrm{~min}$ after oral peanut challenge in week 7 (a) followed by intraperitoneal challenge (b). Rectal temperatures were measured $30 \mathrm{~min}$ after oral challenge (c) and the final intraperito-

IgG2a, median: 11.7 vs. $4.8 \mu \mathrm{g} / \mathrm{ml}$, IQR: 9.73 vs. 1.7 , $\mathrm{p} \leq$ 0.0001 . Similar differences in peanut-specific antibody levels were found between soy-free mice and mice fed the isoflavone diet $(\mathrm{n}=18)$, with IgE, median: $164 \mathrm{vs.} 109 \mathrm{ng} /$ ml, IQR: 169.5 vs. $109.5, p=0.0055$; IgG1, median: 62.4 vs. $26.6 \mu \mathrm{g} / \mathrm{ml}, \mathrm{IQR}: 7.65$ vs. $35.65, \mathrm{p}=0.0012$; IgG2a, median: 11.7 vs. $4.45 \mu \mathrm{g} / \mathrm{ml}$, IQR: 9.73 vs. $1.23, \mathrm{p}<0.0001$ (fig. 4). These data show that elimination of soy from the diet renders mice more susceptible to sensitization to food. The suppression of allergic responses observed in mice on a soy diet (regular chow) can be established by dietary introduction of just 2 isoflavones (genistein and daidzein), which correlated with the serum isoflavone content (online suppl. table 2).

Rodent Dietary Components and Food Allergy in BALB/c Mice neal challenge (d). The change in the body temperature is presented as box-and-whisker Tukey plots. Naïve/unsensitized mice in all diet groups were appropriately challenged with peanut (PN). PBS $=$ Phosphate-buffered saline; isoflavone $=$ genistein + daidzein. Data from 3 independent experiments are shown. ${ }^{*} \mathrm{p}<0.05$, ** $\mathrm{p}<0.01,{ }^{* * *} \mathrm{p}<0.001$.

\section{Dietary Isoflavones Do Not Induce Epigenetic Modifications in IL-4 Promoter}

Isoflavones (especially genistein) have been shown to induce epigenetic modifications [18-20]. To test whether dietary introduction of isoflavones will induce epigenetic modifications of promoter sites of IL-4, we tested the demethylation of specific CpG sequences in 2 sites of the IL-4 promoter region in mouse splenocytes and mesenteric lymph node cells by pyrosequencing (online suppl. fig. 2) [21]. There were no significant changes in percentage of methylated $\mathrm{CpG}$ sequences in DNA obtained from splenocytes (online suppl. fig. $2 \mathrm{a}$ and $\mathrm{b}$ ) or mesenteric lymph node cells (online suppl. fig. $2 \mathrm{c}$ and $\mathrm{d}$ ) from unsensitized (naïve) mice fed soy-free or regular chow. How- 


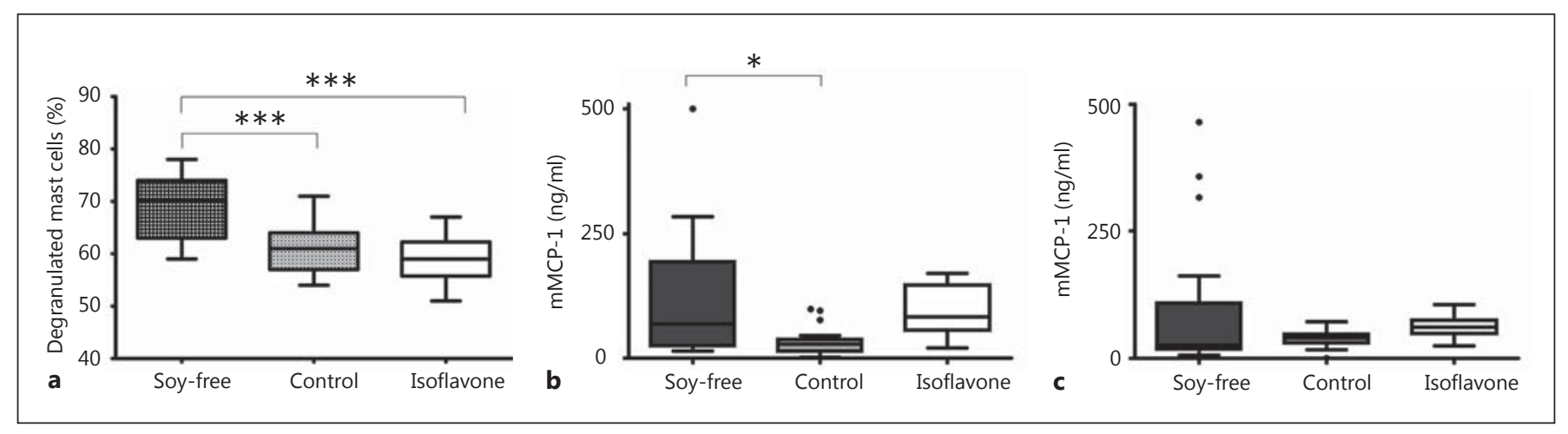

Fig. 3. BALB/c mice maintained with a soy-free diet $(n=21)$, regular chow (control; $n=19$ ) or soy-free mice with an isoflavone diet (genistein + daidzein; $\mathrm{n}=18$ ) were sensitized and challenged with peanut extracts as detailed in the Materials and Methods. The percentages of degranulated mast cells were calculated in histological sections of ears collected within $60 \mathrm{~min}$ after the final intraperito-

ever, the percentage of methylation was drastically decreased in site $\mathrm{i}\left(\mathrm{CpG}^{-408}\right)$ but not site ii $\left(\mathrm{CpG}^{-393}\right)$ in all peanut-sensitized mice (irrespective of exposure to isoflavones for generations), suggesting an upregulation of IL-4 expression (online suppl. fig. 2). These data suggest that dietary isoflavones have a negligible effect on epigenetic modifications induced during the allergic immune response.

\section{Discussion}

Animal models of food allergy have significantly contributed to our understanding of the pathogenesis of food allergy. However, animal models that accurately represent human disease are still lacking [22]. An ideal mouse model for food allergy should demonstrate a high IgE humoral response and robust anaphylaxis following oral allergen challenge. Unfortunately, there are several straindependent variations in the development of allergic responses toward food, and none of the available mouse models fulfill all these criteria. $\mathrm{C} 3 \mathrm{H} / \mathrm{HeJ}$ but not $\mathrm{BALB} / \mathrm{c}$ mice were more susceptible to cow's milk and peanut sensitization [9]. Similarly, oral challenge of $\mathrm{C} 3 \mathrm{H} / \mathrm{HeJ}$, $\mathrm{C} 57 \mathrm{BL} / 6$ and $\mathrm{BALB} / \mathrm{c}$ mice did not lead to any systemic anaphylactic response. $\mathrm{C} 3 \mathrm{H} / \mathrm{HeJ}$ (and to a lesser extent $\mathrm{C} 57 \mathrm{BL} / 6$ ) but not $\mathrm{BALB} / \mathrm{c}$ mice elicited a robust systemic anaphylaxis after peanut intraperitoneal challenge [8]. Our finding of enhanced sensitivity to peanut oral challenge in $\mathrm{BALB} / \mathrm{c}$ mice fed a soy-free diet is significant because of the physiological relevance of sensitization and neal challenge (a). mMCP-1 levels were tested in plasma samples collected within $60 \mathrm{~min}$ after the final intraperitoneal challenge (b) or $30 \mathrm{~min}$ after the oral challenge (c). The results are presented as box-and-whisker Tukey plots. Data from 3 independent experiments are shown. ${ }^{*} \mathrm{p}<0.05,{ }^{* * *} \mathrm{p}<0.001$.

secondary exposure in humans. These results show that $\mathrm{BALB} / \mathrm{c}$ mice can be a useful food allergy model when appropriate dietary modifications and sensitization protocols are employed. By utilizing a soy-free diet, a longer sensitization protocol and a higher concentration of peanut for challenges, we were able to show detectable symptom scores and other indicators of allergic responses in $\mathrm{BALB} / \mathrm{c}$ mice. All these allergic responses were less pronounced in mice fed an isoflavone diet. The mechanism behind the action of isoflavones is at least in part due to their action on mast cell degranulation (fig. 3 ) and suppression of humoral responses against peanuts (fig. 4) which are in line with our previous reports $[10,13]$.

Dietary components are an important factor in shaping the immune response to food allergens. Soybean components in rodent diet provide a large dose of isoflavones and thereby exert its effects on the mucosal response on a continuous basis. The gastrointestinal microbiome and the mucosal membrane-bound lactase phlorizin hydrolase convert the inactive isoflavone glycosides to active aglycones [23, 24]. Therefore, the bioavailability of isoflavones and their effects are much more pronounced at the level of the gastrointestinal tract and are very important for regulating the immune response to food allergens. The phytoestrogen content in animal chow influences many biochemical or morphological end points as well as breeding and health of offspring $[1,25,26]$. However, commercial rodent diets containing significant quantities of phytoestrogens are being used in animal facilities for breeding and maintenance. Although we did not compare the breeding capacity of mice fed different diets, 


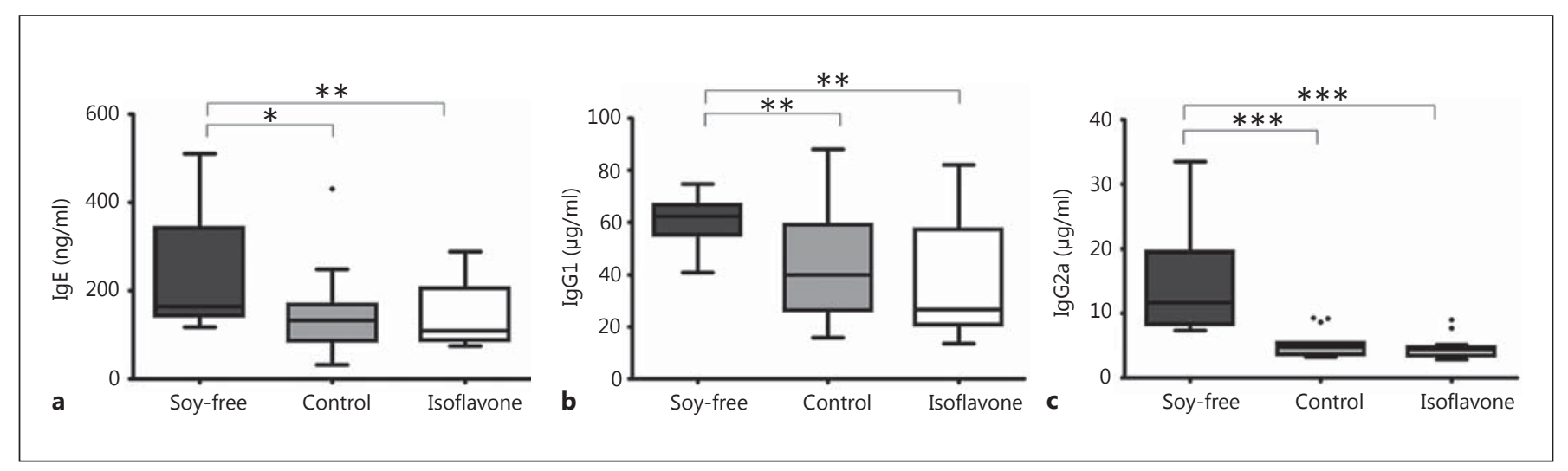

Fig. 4. Peanut-specific serum IgE (a), IgG1 (b) and IgG2a (c) were measured by ELISA at week 6 of sensitization of BALB/c mice maintained with a soy-free diet $(n=12)$, regular chow (control; $\mathrm{n}=19$ ) or soy-free mice with an isoflavone diet (genistein + daid-

there were no detrimental effects or breeding issues with the diet free of soybean components. The soy-free caseinbased diet meets the nutrient specifications of NIH-31 open formula diet which was designed to support gestation, lactation and growth. In addition, we did not observe any significant differences in experimental readouts between male and female mice (data not shown). We show that BALB/c mice, which do not normally show anaphylaxis to food allergens, can become susceptible when ingesting a soy-free diet (fig. 2). Mice maintained on regular soy-based chow are possibly exposed to different isoflavone concentrations over the course of the sensitization protocol due to high batch-to-batch variations in their total aglycone content (online suppl. table 1). Therefore, the differences seen in soy-free versus regular chow are subtle, and the significance is diminished in small sample sizes.

Isoflavones are known to induce epigenetic modifications during cancer pathogenesis $[18,19]$. Epigenetic mechanisms have been implicated in allergic responses $[17,27]$. Maternal peanut allergy was associated with hypomethylation at $\mathrm{CpG}^{-408}$ and $\mathrm{CpG}^{-393}$ of the IL-4 promoter in splenocytes and mesenteric lymph node cells in offspring compared to offspring of naïve mice [17]. Similarly, in an asthma mouse model, antigen plus diesel exposure induced hypomethylation at $\mathrm{CpG}^{-408}$ of the IL-4 promoter, and the degree of methylation at $\mathrm{CpG}^{-408}$ correlated inversely with IgE levels [21]. These reports suggested that the $\mathrm{CpG}^{-408}$ and $\mathrm{CpG}^{-393}$ are functionally important $\mathrm{CpG}$ residues at the IL-4 promoter [21, 28]. However, we did not find any remarkable epigenetic modulation of dietary isoflavones in the promoter region zein; $\mathrm{n}=18$ ). The results are presented as box-and-whisker Tukey plots. Data from 2 independent experiments are shown. ${ }^{*} \mathrm{p}<0.05$, ** $\mathrm{p}<0.01,{ }^{* * *} \mathrm{p}<0.001$.

of IL-4, a key Th2 cytokine for developing allergic responses (online suppl. fig. 2). In this light, one can speculate that the specificity and the mechanism of action of isoflavones vary under different pathological conditions due to the fact that isoflavones affect a number of cell types and have beneficial effects in a number of diseases [6].

In conclusion, we demonstrate that by eliminating soy from the diet, allergic responses can be enhanced and that a single class of phytochemicals (isoflavones) can reverse this response. This dietary manipulation can be a useful tool to study food allergy in mouse strains that are amenable for genetic manipulations. Batch-to-batch variations in isoflavone content in rodent diets $[2,3,7]$ may contribute to fluctuations in the experimental data, especially those involving the immune system. Therefore, it is important to check and control the isoflavone content in rodent diet formulations when designing animal experiments to obtain reliable and reproducible experimental data.

\section{Acknowledgments}

This study was funded by the Jaffe Food Allergy Institute, Icahn School of Medicine at Mount Sinai, New York. The authors would like to thank Ms. Mohanapriya Kamalakannan and Dr. Nan Yang for technical assistance.

\section{Disclosure Statement}

There are no conflicts of interest. 


\section{References}

$>1$ Brown NM, Setchell KD: Animal models impacted by phytoestrogens in commercial chow: implications for pathways influenced by hormones. Lab Invest 2001;81:735-747.

$>2$ Degen GH, Janning P, Diel P, Bolt HM: Estrogenic isoflavones in rodent diets. Toxicol Lett 2002; 128:145-157.

-3 Jensen MN, Ritskes-Hoitinga M: How isoflavone levels in common rodent diets can interfere with the value of animal models and with experimental results. Lab Anim 2007;41:118.

$\checkmark 4$ Ruhlen RL, Taylor JA, Mao J, Kirkpatrick J, Welshons WV, vom Saal FS: Choice of animal feed can alter fetal steroid levels and mask developmental effects of endocrine disrupting chemicals. J Dev Orig Health Dis 2011;2:3648.

5 Thigpen JE, Setchell KD, Ahlmark KB, Locklear J, Spahr T, Caviness GF, Goelz MF, Haseman JK, Newbold RR, Forsythe DB: Phytoestrogen content of purified, open- and closedformula laboratory animal diets. Lab Anim Sci 1999;49:530-536.

6 Masilamani M, Wei J, Sampson HA: Regulation of the immune response by soybean isoflavones. Immunol Res 2012;54:95-110.

$>7$ Heindel JJ, vom Saal FS: Meeting report: batch-to-batch variability in estrogenic activity in commercial animal diets - importance and approaches for laboratory animal research. Environ Health Perspect 2008;116 389-393.

$>8$ Smit JJ, Willemsen K, Hassing I, Fiechter D, Storm G, van Bloois L, Leusen JHW, Pennings M, Zaiss D, Pieters RHH: Contribution of classic and alternative effector pathways in peanut-induced anaphylactic responses. PLoS One 2011;6:e28917.

-9 Morafo V, Srivastava K, Huang C-K, Kleiner G, Lee S-Y, Sampson HA, Li X-M: Genetic susceptibility to food allergy is linked to differential $\mathrm{TH} 2-\mathrm{TH} 1$ responses in $\mathrm{C} 3 \mathrm{H} / \mathrm{HeJ}$ and $\mathrm{BALB} / \mathrm{c}$ mice. J Allergy Clin Immunol 2003;111:1122-1128.

10 Masilamani M, Wei J, Bhatt S, Paul M, Yakir $\mathrm{S}$, Sampson HA: Soybean isoflavones regulate dendritic cell function and suppress allergic sensitization to peanut. J Allergy Clin Immunol 2011;128:1242-1250.
11 Li XM, Serebrisky D, Lee SY, Huang CK, Bardina L, Schofield BH, Stanley JS, Burks AW, Bannon GA, Sampson HA: A murine model of peanut anaphylaxis: $\mathrm{T}$ - and $\mathrm{B}$-cell responses to a major peanut allergen mimic human responses. J Allergy Clin Immunol 2000;106:150-158.

12 Bublin M, Breiteneder H: Developing therapies for peanut allergy. Int Arch Allergy Immunol 2014;165:179-194.

13 Wei J, Bhatt S, Chang LM, Sampson HA, Masilamani M: Isoflavones, genistein and daidzein, regulate mucosal immune response by suppressing dendritic cell function. PLoS One 2012;7:e47979.

14 Masilamani M, Commins S, Shreffler W: Determinants of food allergy. Immunol Allergy Clin North Am 2012;32:11-33.

15 Fritz WA, Coward L, Wang J, Lamartiniere CA: Dietary genistein: perinatal mammary cancer prevention, bioavailability and toxicity testing in the rat. Carcinogenesis 1998;19: 2151-2158.

16 Doerge DR, Churchwell MI, Chang HC, Newbold RR, Delclos KB: Placental transfer of the soy isoflavone genistein following dietary and gavage administration to Sprague Dawley rats. Reprod Toxicol 2001;15:105-110.

17 Song Y, Liu C, Hui Y, Srivastava K, Zhou Z, Chen J, Miller RL, Finkelman FD, Li XM: Maternal allergy increases susceptibility to offspring allergy in association with $\mathrm{TH} 2$-biased epigenetic alterations in a mouse model of peanut allergy. J Allergy Clin Immunol 2014; 134:1339-1345.

-18 Day JK, Bauer AM, DesBordes C, Zhuang Y, Kim BE, Newton LG, Nehra V, Forsee KM, MacDonald RS, Besch-Williford C, Huang TH, Lubahn DB: Genistein alters methylation patterns in mice. J Nutr 2002;132:2419S-2423S.

19 Xie Q, Bai Q, Zou L-Y, Zhang Q-Y, Zhou Y, Chang H, Yi L, Zhu J-D, Mi M-T: Genistein inhibits DNA methylation and increases expression of tumor suppressor genes in human breast cancer cells. Genes Chromosomes Cancer 2014;53:422-431.
20 Sordillo JE, Lange NE, Tarantini L, Bollati V, Zanobetti A, Sparrow D, Vokonas P, Schwartz J, Baccarelli A, Demeo D, Litonjua AA: Allergen sensitization is associated with increased DNA methylation in older men. Int Arch Allergy Immunol 2013;161:37-43.

21 Liu J, Ballaney M, Al-alem U, Quan C, Jin X, Perera F, Chen LC, Miller RL: Combined inhaled diesel exhaust particles and allergen exposure alter methylation of $\mathrm{T}$ helper genes and IgE production in vivo. Toxicol Sci 2008; 102:76-81.

22 Berin MC, Masilamani M: Experimental approaches to the study of food allergy; in Metcalfe DD, Sampson HA, Simon RA (eds): Food Allergy: Adverse Reactions to Foods and Food Additives. Oxford, Blackwell Publishing, 2012.

23 Day AJ, Canada FJ, Diaz JC, Kroon PA, McLauchlan R, Faulds CB, Plumb GW, Morgan MR, Williamson G: Dietary flavonoid and isoflavone glycosides are hydrolysed by the lactase site of lactase phlorizin hydrolase. FEBS Lett 2000;468:166-170.

$24 \mathrm{Xu}$ X, Harris KS, Wang H-J, Murphy PA, Hendrich S: Bioavailability of soybean isoflavones depends upon gut microflora in women. J Nutr 1995;125:2307-2315

25 Souzeau E, Bélanger S, Picard S, Deschepper $\mathrm{CF}$ : Dietary isoflavones during pregnancy and lactation provide cardioprotection to offspring rats in adulthood. Am J Physiol Heart Circ Physiol 2005;289:H715-H721.

-26 Westmark CJ, Westmark PR, Malter JS: Soybased diet exacerbates seizures in mouse models of neurological disease. J Alzheimer Dis 2013;33:797-805.

$\checkmark 27$ Harb H, Renz H: Update on epigenetics in allergic disease. J Allergy Clin Immunol 2015; 135:15-24.

28 Niedzwiecki M, Zhu H, Corson L, Grunig G, Factor PH, Chu S, Jiang H, Miller RL: Prenatal exposure to allergen, DNA methylation, and allergy in grandoffspring mice. Allergy 2012; 67:904-910. 